\title{
SOCIOLOGIA DISPOSICIONALISTA E CLASSES SOCIAIS: reflexões sobre desigualdade
}

\author{
DISPOSITIONAL SOCIOLOGY AND SOCIAL CLASSES: \\ an essay on inequality
}

\author{
Ricardo Visser*
}

\begin{abstract}
Resumo
A principal finalidade do artigo desdobra-se em dois níveis: a) promover uma discussão acerca do elo entre trajetória de classe e socialização, elegendo como foco a maneira pela qual Pierre Bourdieu (1979) e Bernard Lahire (2001a) encaram esta problemática. O primeiro autor busca construir um plano analítico mais abrangente, considerando processos de socialização como sistemáticos. Já Lahire questiona a homogeneidade das disposições inclinando-se para uma sociologia das figurações e dos modos de socialização; b) em seguida será reconstruído o debate sobre o elo entre origem familiar de classe e variações intraindividuais. A importância deste tema repousa na tentativa de evitar que um viés sociológico confira um poder de sobredeterminação analítica à origem social de classe. Aliamos, finalmente, as teses acerca da variação intraindividual à da multidimensionalidade da desigualdade, a fim de questionar o modelo teórico baseado na socialização familiar de classe e no reforço mútuo da dominação simbólica entre os campos.
\end{abstract}

Palavras-chave: Classes sociais. Socialização. Desigualdade. Sociologia disposicionalista.

\begin{abstract}
The purpose of this article unfolds itself in two levels: a) the debate on the rapport of social classes and socialization processes, focusing on the way Pierre Bourdieu and Bernard Lahire face this problem. Bourdieu tries to introduce a broader analysis considering fields and institutions, taking socialization as a systematic process. On the other hand, Lahire questions the homogeneity of dispositions inclining towards a sociology of figurations and modes of socialization; b) secondly we will discuss the link between familial class origin and individual variations. The importance of this theme resides in the attempt of avoiding the over determination of class origin. Finally, we unite both the thesis of intra individual variations and multidimensionality of inequality in order to question the theoretical model centered on familial class socialization and the mutual reinforcement of symbolic dominations between fields. The intention is to understand the plurality and the heterogeneity of dispositions without losing a more acute deliberation on social domination of sight.
\end{abstract}

Keywords: Social classes. Familial class socialization. Inequality. Dispositional sociology.

A temática principal do artigo será discutir como é possível repensar uma teoria de classes à luz da sociologia disposicionalista, levando em conta o relativo desencaixe entre as vantagens angariadas na socialização familiar de classe e as variações intraindividuais que se manifestam na ação social. Desse modo, o ponto central consiste em discutir a extensão heurística das vantagens e desvantagens materiais e simbólicas inscritas na socialização familiar. A partir deste diagnóstico propomos refletir sobre o elo entre condicionamento da origem de classe e variações intraindividuais. Adentraremos como Bourdieu (1979) e Lahire (2001a)

\footnotetext{
* Doutor em Sociologia pela Universidade Federal de Juiz de Fora, com estágio doutoral na Humboldt Universität zu Berlin, Alemanha. É pesquisador pós-doutoral no Programa de Pós-graduação em Direito da Universidade do Estado do Rio de Janeiro (UERJ). Participou da pesquisa que culminou no livro Reproduktion sozialer Ungleichheit in Deutschland (Rehbein, 2015) e entre 2015-2016 trabalhou no Instituto de Pesquisa Econômica Aplicada. E-mail: ricardovis@gmail.com
} 
divergem a esse respeito na formulação de suas teorias da ação e igualmente em suas análises sobre a intersecção entre a organização familiar e a socialização educacional. Por fim, debateremos o elo entre a diferenciação dos campos e a pressuposição de reforço mútuo da dominação simbólica.

Na primeira parte do artigo, a relação entre classe social e socialização será discutida a partir do enfoque que Bourdieu e Lahire conferem às suas respectivas sociologias. Se para Bourdieu, o conceito de classe deve remontar a uma sociologia em nível institucional ou dos campos relativamente autônomos, nos quais a sistematicidade das disposições é presumida, Lahire valoriza, sobretudo, o plano das interações, empreendendo estudos de modos de socialização, figurações e em escala individual.

$\mathrm{Na}$ segunda seção será debatido o elo entre origem familiar de classe e variação intraindividual. A importância deste tema consiste na tentativa de evitar um viés sociológico que confira à origem familiar de classe - suas respectivas vantagens e desvantagens - um poder de sobredeterminação analítica. Discutiremos exploratoriamente as consequências da sobredeterminação da origem familiar de classe para a dimensão operacional das instituições. Por fim, faremos uma apreciação crítica de uma sociologia da desigualdade baseada na primazia excessiva da socialização familiar de classe, contrapondo-a tanto aos desenvolvimentos da sociologia em escala individual quanto à reflexão acerca da multidimensionalidade da desigualdade.

Concluiremos com um balaço sobre as temáticas discutidas, com um apontamento final sobre possíveis desdobramentos da reflexão.

\section{Classe e socialização em Bourdieu e Lahire}

O liame entre socialização e pertencimento de classe foi primeiramente explorado por Bourdieu (1979). Em sua perspectiva, a incorporação de tendências pré-reflexivas para ação, categorias de pensamento e percepção ocorre de modo durável. Coloca ainda a socialização familiar de classe como um processo de transmissão de habilidades e competências culturais e escolares. Lahire (2001a, 2012), por sua vez, questiona o caráter sistemático e homogêneo dos processos de socialização, procurando questionar sua abstração num sistema, demonstrando sua dimensão acidental e não linear. Lahire se recusa ainda a reduzir os processos de socialização familiar como meras formas de transmissão de competências ou desvantagens culturais.

Segundo Pierre Bourdieu, o habitus ${ }^{1}$ é o princípio gerador das práticas, o conceito que torna inteligível e confere racionalidade sociológica à ação social. Ele constitui um sistema integrado de práticas de disposições. Além de conferir racionalidade e inteligibilidade às disposições, ou

1 A concepção relacional da realidade na qual se apoia a sociologia bourdieusiana serve também para a relação interna entre seus conceitos. A distinção entre habitus, campo, classe e espaço social é meramente analítica e existente de forma imbricada na realidade empírica. 
seja, às tendências para a ação, o habitus incute no agente a habilidade de distinguir e classificar as disposições e práticas dos outros (BOURDIEU, 1979). Esta capacidade avaliativa torna-se operante tanto na dimensão pré-reflexiva quanto na consciente das interações cotidianas, por meio das categorias de pensamento. Em outras palavras, da mesma forma que o habitus estrutura (modus operandi) classificações, categorias de pensamento e divisões de mundo, tais operações ocorrem de acordo com classificações e divisões anteriores (opus operantum), orientando suas novas classificações (estruturações). A estabilidade ou reprodução do habitus frequentemente depende de seu pertencimento de classe ${ }^{2}$, posto que constrange os agentes a possibilidades estabelecidas e inscritas nos campos relativamente autônomos.

Portanto, em sociedades modernas e diferenciadas, o processo de socialização trazido pelo habitus de classe é central, se desdobrando em dois planos: o habitus de classe é passível de classificação objetiva, ou seja, comportamentos, práticas e as disposições nele inscritas são alvos de juízos e atribuições de terceiros e; b)ele incute, no agente, categorias de pensamento cotidianas por meio de uma experiência marcada pelo pertencimento de classe: o habitus é o princípio de organização da experiência, o princípio gerador das práticas objetivamente classificáveis e sistema de classificação (principium divisionis) destas práticas (BOURDIEU, 1979). Assim sendo, ele opera tanto sob a forma de esquemas de pensamento, ou seja, enquanto consciência prática, quanto no plano pré-reflexivo, guiando e orientando as práticas dos agentes, uma vez que é produto de um processo de aprendizado e incorporação.

Com isso, o critério de demarcação da classe social deixa de ser propriamente a posição do agente nas relações de produção, passando a ser coordenado por um habitus de classe, vinculado a uma trajetória e a uma posição num campo relativamente autônomo. A ênfase passa a ser a socialização de classe. Se o habitus de classe se comporta tendencialmente como um sistema, é pelo fato de ele também presumir disposições "sistematicamente transferíveis" (BOURDIEU, 1979, p. 192). Nesse sentido, uma prática possui grande probabilidade de se reproduzir, de se perpetuar através de disposições duráveis. A incorporação de um conjunto de disposições é geralmente, para Bourdieu, um investimento afetivo de longo prazo. O lócus primário da socialização de classe é identificado por Bourdieu na organização familiar.

Não obstante, seria impreciso imputar na categoria de habitus uma existência material direta, já que um dos esforços de Bourdieu era precisamente demonstrar que conceitos não existem em si na realidade empírica, mas são parcialmente constructos intelectuais que lhes conferem coerência. Quer dizer, eles existem apoiados no incessante trabalho empírico e interpretativo. $\mathrm{O}$ conceito de classe social é, em parte, uma abstração do analista para compreender; por outro, deve corresponder à maneira real pela qual os agentes se distinguem, classificando e sendo classificados.

Deste ponto de vista, salvo algumas exceções, não parece haver nem incongruência tampouco tensões entre o conceito de habitus, tomado enquanto disposições e inclinações

2 Certamente existem outras formas de pertencimento, princípios de socialização e classificação além da classe, como gênero e raça. Por motivos temáticos, enfatizamos a socialização de classe. 
à ação, e o pertencimento de classe. Em suma, ao implicar um caráter sistêmico, associa-se à categoria de habitus a de classe social com invejável facilidade. Contudo, para desenvolver uma sociologia disposicionalista em escala individual seria necessário se perguntar: como se constituem as disposições? Como e por que elas se reatualizam ou não? Ou ainda, como uma realidade exterior mais ou menos heterogênea é feita corpo? (LAHIRE, 2001a). Ao passo que os agentes incorporam disposições, formas de agir inculcadas afetiva e intelectualmente, estas se cristalizam em inclinações à ação e em signos manifestos no corpo socializado. Por este motivo, Lahire critica a forma imprecisa e bastante vaga pela qual Bourdieu define descritivamente as diferentes manifestações do habitus (LAHIRE, 2001a). De acordo com essa crítica, a definição de Bourdieu (1979) perde precisão por ser caracterizada por meio de adjetivos e substantivos, sem que possamos efetivamente compreender como elas são ativadas, fomentadas, constrangidas ou inibidas de acordo com o contexto social no qual o agente está inserido. Se considerarmos patrimônios de disposições, como Lahire o faz, um conjunto de disposições estruturadas pode ou não se tornar estruturante, isto é, pode ou não se tornar disposições realizadas, concretizadas em práticas. Sua reprodução depende de contextos de atualização, o que não necessariamente se confunde com o espectro de disposições observáveis nos campos. Esta ideia ajuda muito a entender, por exemplo, a irregularidade nas trajetórias de classe - em vez de supor sua linearidade. Ao enfatizar o poder integrador do habitus, Bourdieu (1979) endossa a ideia de que existe uma tendência permanente à reprodução social. Com isso, Bourdieu abstrai o contexto de atualização de disposições, para usar a terminologia de Lahire (2001a). Ainda que prescrito em forma teórica, a sociologia bourdieusiana permanece carente de um plano analítico capaz de apreender os processos de socialização, com seus acidentes, contingências e descaminhos.

Se Bourdieu pretende superar a dicotomia entre a formação de estruturas objetivas e sua incorporação cotidiana, não se pode pressupor sua inércia, como se disposições (bem como os capitais que elas engendram) se reafirmassem à revelia do esforço cotidiano de inculcação de disposições: a "transmissão" desse capital obedece a um trabalho incessante, diário, de longo alcance e às vezes doloroso tanto para os filhos como para os pais (LAHIRE, 2002, p. 29). Aliás, o ambiente familiar deve ofertar um contexto de transmissão para o capital cultural, o que nem sempre se arranja dentro da divisão do trabalho doméstico (LAHIRE, 2012). Ao invés de preconcebermos a homogeneidade do habitus, seria teoricamente mais preciso estabelecer até que ponto se observa a sistematicidade das disposições. A coerência interna do habitus dependerá muito mais dos princípios de socialização (LAHIRE, 2012) nos quais um agente está ou esteve imerso. A pesquisa sociológica deve ser, portanto, uma investigação sobre os modos de socialização. Ademais, Lahire (2012, p. 188) comenta que a socialização educacional no seio familiar não se constitui tão somente através da "transmissão do capital cultural", mas também por meio de relações com a escrita, com a escola, angústias, humilhações etc., Lahire quer chamar a atenção para esquemas valorativos e atitudinais emergentes destes processos de socialização. 
A pluralidade relativa das disposições proporciona uma análise mais aproximada da realidade sem, entretanto, pressupor automaticamente a atualização de disposições incorporadas. Esta incoerência do patrimônio de disposições é devida à diversidade de vínculos de pertencimento, matizes e matrizes de socialização nas quais o indivíduo moderno se encontra inserido. Daí sua heterogeneidade constitutiva. Se estamos imersos numa pluralidade de campos referidos a lutas simbólicas específicas, certamente os indivíduos não "investem" afetivamente com a mesma força e vigor nos campos. Os vários campos não são homogêneos e se referem a um conjunto de exigências específicas: "Somos, portanto plurais, diferentes nas diversas situações da vida comum, estranhos às outras partes de nós mesmos, quando estamos investidos em tal ou tal domínio da existência social. " (LAHIRE, 2002, p. 39). A realização das disposições seria, então, tributária do seguinte esquema: o passado incorporado do ator + contexto de atualização. A contingência entre esses dois elementos equivale à heterogeneidade da agência. Para que tenhamos uma teoria da prática mais sofisticada e empiricamente mais refinada, seria preciso confrontar e investigar tanto a força ou a "durabilidade" das disposições referentes a um contexto quanto a sua possibilidade de confirmação ou inibição. Por isso, o deslizamento sutil do potencialmente transferível e generalizável à transferência e à generalização empiricamente constatadas e atestadas (LAHIRE, 2002). Desse modo, Lahire problematiza tanto a homogeneidade na intensidade das disposições quanto a generalidade das condições de transmissão de regras e disposições, sobretudo, no tocante ao capital cultural necessário ao sucesso escolar.

Aqui, a crítica acertada a Bourdieu se endereça ao fato de que nem sempre disposições são vivenciadas enquanto "transformação de necessidade em virtude" ou como paixão. Então, é tarefa da sociologia explicar o conjunto de dinâmicas que conferem intensidade e extensão às práticas (LAHIRE, 2006). Por certo, para responder a esta pergunta, Lahire admite a possibilidade incessante de aprender ou não novas disposições. Contudo, há uma diferença notável entre as etapas de socialização: será que, mais velhos, podemos aprender uma língua estrangeira com a mesma desenvoltura que uma criança? Ademais, como destacaram Adorno (2003) e Fromm (MACIEL, 2018) a cultura capitalista, com sua indústria cultural e de propaganda, pende à padronização da experiência humana reificando e coisificando nossa identidade. Nossa espontaneidade individual fricciona-se cada vez mais com comportamentos rotinizados objetivamente impostos, sem que nós os percebamos como tal (caráter social do homem médio). Não seria igualmente possível imaginar que a capacidade de desenvolver aspectos heterogêneos das disposições mantém algum tipo de vinculação com as chances de individuação e diferenciação disposicional que o pertencimento de classe lega ao agente?

Neste ponto, temos um feixe de debate importante: de um lado, a abertura total às potencialidades de aprendizado durante a trajetória de um indivíduo; de outro, um précondicionamento disposicional primário a depender da posição resultante do entrecruzamento entre posição de classe e família. Tomemos o exemplo da relação entre família e sistema 
educacional, sendo a primeira responsável pelo trabalho de inculcação primário e o segundo pelo trabalho pedagógico subsequente (BOURDIEU; PASSERON, 1970). Tal distinção enquadra-se numa síntese entre as práticas engendradas no habitus e o trabalho pedagógico educacional. O louvável esforço de Bourdieu em construir uma sociologia institucional do sistema de ensino recai na primazia socializadora do ambiente familiar. A família, localizada numa posição de classe, é a principal responsável pelas desvantagens educacionais incorporadas em práticas e disposições, refletidas posteriormente em posições finais na hierarquia escolar, universitária, ou no mercado de trabalho. Em congruência com esta assertiva, o autor enfatiza a função integradora do habitus (BOURDIEU; PASSERON, 1970), sendo todo trabalho pedagógico secundário uma função da distância com relação ao trabalho pedagógico primário (arbitrário cultural original) e seu habitus correspondente (BOURDIEU; PASSERON, 1970). Sob este prisma, o contexto familiar de uma classe social torna-se a principal matriz estruturante original de vantagens ou desvantagens. Um exemplo patente deste raciocínio em Bourdieu é observável na principal estratégia de distinção mobilizada pela burguesia de forte formação cultural (os herdeiros): a naturalidade desenvolta (disfarçada de talento) com a cultura legítima. Sob cláusula de precedência, esta última torna-se incorporada no seio familiar, em contraste com a socialização demasiadamente "escolar", maquinal e rotinizada das classes médias, ou mesmo lacunar da pequena burguesia.

Para Lahire (2012), o problema com este tipo de abordagem repousa em duas vertentes de raciocínio. A primeira delas é que Bourdieu e Passeron (1970), em nome de uma sociologia relacional do sistema educacional, não atentam nos modos específicos de socialização familiar com respeito ao sistema educacional e à cultura escolar. Para compensar isso, permanecem em tipologias descritivas do habitus. Eis o impasse. Nas classes populares, podemos citar ao menos três eixos que apontam para os modos de socialização educacional na família, identificados por Lahire. ${ }^{3}$ Os tipos de punição, o grau de racionalização do cotidiano e os contextos nos quais se trata de afazeres escolares no ambiente familiar. Evitei deliberadamente o termo contexto de transmissão porquanto nem sempre o que se transmite é um "capital cultural". Os eixos

\footnotetext{
3 Para um ponto de vista comparativo com as classes médias ver: Le "métier denfant ". Définition sociale de la prime enfance et fonctions différentielles de lécole maternelle, de Jean-Claude Chamboredon e Jean Prévot. O texto abarca tanto as pré-condições culturais e econômicas sobre as quais as classes médias e dominantes dispõem para dedicarem o tempo materno ao cuidado afetivo e à transmissão do capital cultural, bem como à construção da criança como objeto de um trabalho pedagógico. Por outro lado, ela pode tornar-se sujeito e fonte de curiosidades e expressão singular, que ganham especial valor em modelos institucionais educacionais que adotam procedimentos avaliativos mais flexíveis. $\mathrm{O}$ trabalho pedagógico transforma-se em um ato de negociação com a criança, ao invés da pura imposição de um arbitrário cultural. Por sua vez, Basil Bernstein mostrou com argúcia como o novo modelo pedagógico no qual o aluno não é mais exclusivamente visto como objeto da comunicação pedagógica - mas também sujeito de interesses e habilidades singulares escolarmente válidas - culminou no beneficiamento de uma nova classe média engajada no setor de serviços de controle simbólico. Ainda que ele não defina precisamente esse termo, não seria impossível imaginar ocupações que dependam de um capital cultural técnico-estético. Ele ainda aponta que este novo modelo de trabalho pedagógico estimula o desenvolvimento de estratégias de controle inter e intrapessoal. Outro aspecto central é que, para esta nova classe média, não há a segmentação tão abrupta entre contextos lúdicos e de trabalho, fomentando um tipo de pedagogia implícita e "naturalizada". Ver Basil Bernstein (1975).
} 
temáticos são interligados. As análises se dão no âmbito de sua pesquisa sobre socialização escolar e familiar nos meios (millieux) populares.

No primeiro deles, a punição, Lahire (2012) atesta uma distinção entre tipos de punição. Uma visa, de início, à sanção de uma transgressão; a outra, mais disciplinar, produz efeitos disciplinares mais efetivos. Nota-se que, apesar de normalmente envolver um rito punitivo, as punições corporais (o que não significa a ausência de comunicação) englobam algum tipo de permissividade, seguida de baixa vigilância (LAHIRE, 2012). Sob este espectro, as sanções corporais tratam mais o sintoma (a transgressão de uma regra) e têm baixo potencial preventivo. Normalmente, este tipo de socialização familiar com relação às tarefas escolares obedece a uma contradição performática: há sanções para as crianças quando não cumprem os afazeres escolares, mas os responsáveis são incapazes de servir como "bom exemplo", ou seja, como portadores de práticas cotidianas escolarmente reconhecidas. Em famílias nas quais há crianças com melhor desempenho escolar, Lahire destaca que a intensidade das sanções que geram autodisciplina é moderada, denotando a compreensão dos responsáveis de que o aprendizado é um processo orientado para o futuro abstrato.

O segundo eixo versa sobre o grau de racionalização do cotidiano. Lahire nota que nas famílias nas quais há um cotidiano racionalizado, as atividades domésticas e escolares são repartidas no tempo. Aqui, observa-se igualmente uma mediação e um uso mais acentuado da linguagem escrita no dia-a-dia (lista de compras, uso do calendário, bilhetes, leitura de livros, etc.). É como se estas famílias gerissem o cotidiano. Em associação com estas configurações familiares, constata-se um antecipado espírito de competição "querer ser o/a melhor da turma”, afinado com a compreensão do sistema educacional como veículo de ascensão social (ABRANTES; AMÂNDIO, 2014, p. 16). Tais ações estratégicas tornam-se precocemente incorporadas nas classes populares analisadas por Bernard Lahire.

Por último, ele examina a teoria da transmissão ou da generalidade de transposição do capital cultural. No tocante aos modos de socialização educacional nas famílias das classes populares, Lahire (2012) sublinha dois alicerces temáticos. Um deles é o fato de que nem sempre o responsável com maior grau de incorporação de capital cultural e escolar encontra-se disponível para "transmitir" e socializar a criança. Aqui, por certo, as condições laborais nas quais pais ou responsáveis se encontram é fator primordial. Além disso, faz-se necessário compreender se o agente socializador dispõe de disposições adequadas. Os pais ou os responsáveis podem ter incorporado um capital cultural escolarmente valorizado, sem, no entanto, desfrutar das habilidades necessárias para transmiti-lo. Uma indagação crítica plausível seria refletir sobre a ausência de uma análise comparativa entre classes, dado que as famílias de classe média estabelecida, como vimos com Chamboredon e Prévot (1973), dispõem de condições econômicas (tempo fora do trabalho) e culturais (maior desenvoltura com a cultura escolar) mais confortáveis para agir pedagogicamente em relação às crianças. 
Lahire então analisa como as experiências escolares pregressas dos pais ou responsáveis condicionam a socialização educacional dentro do ambiente familiar. Com isso, descobre-se que um sentimento de forte frustração educacional, ainda que seja uma breve experiência com a cultura escolar, pode exibir efeitos mais perversos do que em pais e responsáveis analfabetos (LAHIRE, 2012). Com o estabelecimento de elos afetivos e disciplinares cotidianos, mesmo que os pais e responsáveis não entendam totalmente o que seus filhos fazem na escola, uma experiência positiva pode emergir em verbalizações e conversas nas quais a admiração dos pais pode se reverter em autoestima para a criança.

Ao considerarmos a sociologia da educação em Lahire, Bourdieu e Passeron, chegamos à conclusão de que, conquanto não sejam completamente antagônicos, os focos da análise são dessemelhantes. Enquanto Bourdieu e Passeron (1970) buscam uma sociologia do sistema de ensino e seu complexo institucional, cuja reprodução de desigualdades de classe na origem tornase obnubilada pelos procedimentos de seleção e avaliação, Lahire (2012) envereda pela questão das desigualdades educacionais a partir de uma sociologia dos modos de socialização com a cultura escolar nos ambientes familiares. De certa maneira, se Bourdieu e Passeron ponderam de maneira mais veemente sobre as determinantes sistêmicas e institucionais da desigualdade, o enfoque notadamente disposicionalista de Lahire -também inspirado por estudos de figurações iniciados por Norbert Elias e Scotson (1993) - abre mais espaço para análise de contextos perpassados por contingências. Com isso, privilegia-se uma sociologia dos processos. Os eventuais descaminhos de uma trajetória podem, ou não, confirmar desvantagens de origem de classe.

A finalidade principal da seção foi demonstrar a fragilidade da concepção de Bourdieu (1979) acerca da linearidade total e do excessivo poder integrador do habitus. Num segundo momento, Lahire (2001a), conquanto essencialmente não contradiga Bourdieu, demonstra, em seu livro sobre o sucesso escolar nas classes trabalhadoras, que a socialização familiar de classe engloba mais do que a transmissão do capital cultural. Com isso, torna-se factível ponderar criticamente a respeito da sobredeterminação da socialização familiar de classe. Este raciocínio se confirma, sobretudo, no tocante ao seu poder de restrição de chances de vida futuras na trajetória de um agente.

\section{Variação intraindividual e multidimensionalidade da desigualdade}

Nesta seção vamos discutir as dificuldades de uma teorização de uma dominação simbólica global do ponto de vista da sociologia em escala individual, que por definição busca apreender a heterogeneidade relativa das disposições. Também arrolaremos o debate acerca da multidimensionalidade da desigualdade, refletida na teoria dos campos de Bourdieu. No entanto, embora sensível à diferenciação dos campos, cremos que sua concepção tende a postular uma correspondência entre a primazia da socialização familiar de classe e o reforço mútuo da estrutura de dominação encontrada nos campos. 
O tema da dominação social é recorrente na sociologia. Pierre Bourdieu procurou introduzir conceitos como habitus, campo e espaço social, de modo a conciliar a dimensão institucionalizada e a cotidiana, mediada por interações intersubjetivas e processo de socialização.

Este é o caráter propriamente genético ou genealógico da sociologia bourdieusiana, que aventou explicar por que o mundo se dá desta maneira e não de outra. A dominação evolui no cotidiano a partir de lutas simbólicas nele ancoradas. Uma sociologia que pretende construir categorias para apreender a estruturação histórica do mundo social é ela própria igualmente tributária, assim, da formulação dos princípios ou condições sociais da produção da representação legítima. Por isso, a inclusão da contingência sócio-histórica na noção de estrutura social conduz Bourdieu a explicitar as condições de produção histórico-sociais da dominação. Assim, ele empreende uma crítica à sociologia espontânea que, não questionando a gênese política e histórica de seus próprios conceitos, permanece analiticamente superficial. Pode-se assegurar, então, que além de situada e dependente de condições históricas específicas à sua imposição, a dominação simbólica contém uma cláusula de arbitrariedade. Portanto, a luta e a dominação simbólica consistem efetivamente nos meios com os quais as classes dirigentes dispõem para controlar e impor certa visão de mundo culturalmente ancorada e tacitamente operante por meio de procedimentos institucionalizados, como acontece no sistema educacional. Sob este espectro, não há propriamente um valor intrínseco ao estilo de vida e ao gosto burguês. ${ }^{4} \mathrm{Em}$ contraste, sua significância reside na sua aparente universalidade, que dissimula as condições de acesso ao uso e à prática habilidosa de suas regras. Não por acaso, a maneira mais eficaz de imposição simbólica de uma classe a outra é produzir o reconhecimento subentendido e inquestionável das regras, convenções, práticas e condutas que compõem os gostos, os estilos de vida, esquemas de classificação e pensamento das classes dominantes. Sua cristalização em procedimentos institucionalizados contribui à aceitação das regras do jogo social sem o devido conhecimento de suas regras e cláusulas pétreas. Assim sendo, as classes dominadas contribuem de modo pré-reflexivo à sua própria dominação.

Apesar de a sociologia bourdieusiana da dominação simbólica ter exercido impacto em Lahire, sua sociologia busca conciliá-la com o plano das variações intraindividuais. Decerto, embora jamais negue a existência de desigualdades de classe, constitutivas de qualquer sociedade moderna, sua atenção se endereça a processos de socialização que não podem ser diretamente imputados à luta simbólica de classes. Em certo sentido, podem até mesmo desafiá-los. Consequentemente, o cientista social deve começar por “(...) examinar as diferenças internas de cada indivíduo (variações intraindividuais) antes de mudar o ângulo de visão e de enfocar as diferenças entre classes sociais (variações interclasses) ” (LAHIRE, 2006, p.17). Nessa passagem, Lahire esmiúça justamente uma propositura teórica na qual o patrimônio de

4 Certamente não está na alçada de Bourdieu (1979) desvalorizar por completo a cultura burguesa, mas apontar para o diagnóstico de que, no presente período histórico de seu desenvolvimento, ela prima pela reprodução de um letramento fútil e pelo erudicionismo vazio, sobretudo, no campo acadêmico. 
disposições do agente, além de não necessariamente compor uma unidade lógica tampouco empírica, não pode ser totalmente inferido de comportamentos herdados na posição original de classe. Do ponto de vista histórico e comparativo, apesar de a generalização de direitos sociais e a expansão educacional em países sociais-democratas não terem abolido a desigualdade no seio da origem de classe, ela proporcionou a flexibilização de seus mecanismos de tal modo que nem as disposições, nem a identidade e tampouco a trajetória dos agentes se conformam ao princípio unificado contido no contexto familiar de sua classe de origem. Como resultante, torna-se plausível certo afrouxamento na correlação entre formas de desigualdade de origem, reproduzidas em subsistemas funcionalmente diferenciados, campos relativamente autônomos e a formação de tendência à ação. Estas diferentes formas de desigualdade de origem consistem em desvantagens educacionais, econômicas, familiares, de consumo cultural, em relações pessoais capitalizáveis, acesso à saúde, desigualdade de gênero, raça, etc., de modo que nenhuma destas searas possa ser reduzida restritamente à outra, pois operam como regras e normas relativamente especializadas. Assim sendo, o desacoplamento parcial (e jamais total) entre, de um lado, as etapas primárias da socialização de classe nos campos e esferas de ação, as condições objetivas iniciais que se apresentam a um agente; e, de outro, o feixe de limites e possibilidades de sua trajetória, condicionados pela espécie e pelo volume dos capitais incorporados ou obtidos, confere maior relevância sociológica às variações individuais. Para Lahire (2001a), parece haver mais uma fundamentação teórico-metodológica. Enquanto a motivação metodológica orbita em torno da necessidade de vigilância epistemológica quanto à estabilidade de comportamentos incorporados durante uma trajetória, a teórica visa evitar generalizações abusivas, nas quais o cientista social pressupõe de antemão a harmonia sistêmica entre as disposições nos campos relativamente diferenciados (LAHIRE, 2001b).

Se Bourdieu $(1979,1970)$ oferece um modelo de socialização de classe baseado em esquemas mentais e de comportamento herdados na família, os quais se encontram num feixe de limites e possibilidades na hierarquia de classes, Lahire (2012) busca compreender a socialização primária de classe não mais como sobredeterminação de chances futuras. Para tanto, faz-se necessário recuperar uma sociologia disposicionalista e dos modos de socialização, em vez de inferi-los de seus efeitos institucionalizados.

Bourdieu (1993) ainda aplica o conceito de campo ao ambiente familiar no qual há constantes relações de força e conservação. Afirma-a, portanto, como lócus de luta por interesses. Parece-nos que muito embora operantes, tais funções sociais necessitam de um lastro moral objetivado (já independente de eventuais variações contextuais e psicológicas) sobre o qual tais disputas podem tomar lugar (HONNETH, 2012). Por lastro moral familiar entendemos a consolidação de práticas baseadas no cuidado afetivo, na incorporação profunda de disposições disciplinares e no senso de responsabilidade mútua entre os membros. Tratam-se de etapas absolutamente fundamentais na consolidação de uma relação prática positiva dos agentes consigo, calcada em confiança e autoestima. Daí sua abrangência transclassista. Em acordo com 
Honneth, Lahire (2012) parece estar mais sensível a esta dimensão, muito embora não oferte uma teoria social que contribua à percepção da moderna função normativa da organização familiar na formação do indivíduo.

Isto posto, o debate entre Bourdieu e Lahire acerca da reprodução da desigualdade de classes aponta tanto para sua multidimensionalidade, na qual um fator isolado não serve de causa única aplicável a todos os fenômenos sociologicamente relevantes, quanto para a dinâmica entre o passado social e a contingência das variações intraindividuais. Em face disso, um patrimônio de disposições comporta um conjunto de práticas e comportamentos capitalizáveis, ou não, nos campos relativamente autônomos, nos quais podem vir a se friccionar com vantagens e desvantagens angariadas na origem familiar de classe.

A teoria da dominação simbólica de Bourdieu (1979) congrega a dimensão histórica ao seu caráter multidimensional, uma vez que se reproduz em domínios de ação relativamente autônomos, a saber, os campos. Neste registro, os campos constituem regimes de ação com regras diferenciadas entre si. Não obstante, em Bourdieu, apesar de serem regimes relativamente autônomos, os campos exibem uma estrutura comum, detalhada por Lahire (2001b). Eles consistem, pois, em arenas de batalhas simbólicas e culturais pela distinção e pelo controle das espécies de capitais, sendo o espaço social sua representação abstrata (BOURDIEU, 1979). A teoria dos campos assinala, então, a resposta de Bourdieu à completa impossibilidade de explicar corretamente o poder e a dominação simbólica em sociedades modernas sem uma teoria da diferenciação social. A ideia de autonomia relativa, ou seja, de que cada campo cria regras, procedimentos próprios, implicando padrões de disposições e habitus especializados, não significa que não haja a possibilidade de interpenetração dos campos e efeitos de homologia. Entretanto, o que nos parece mais problemático é a sutil unidade da desigualdade que perpassa todos os campos. Em congruência com a primazia da socialização familiar de classe, tem-se a impressão de inevitável reforço mútuo da dominação em todos os campos, o que de modo algum trai a força integradora do habitus de classe em relação às disposições.

Em texto sobre classes sociais, Niklas Luhmann (1985) oferta-nos uma perspectiva consequente a respeito do elo entre classes sociais e a inevitável multidimensionalidade da desigualdade em sociedades modernas, ou seja, entre diferenciação funcional e estratificação social. Conquanto ignore a dimensão das disposições, há uma nuance com relação à visão de Bourdieu. Segundo o autor, o critério fundamental para formação das classes é saber se privações e desvantagens num determinado aspecto da vida (renda, prestígio, saúde, educação, assistência familiar, etc.) conformam-se em prováveis privações e desvantagens noutras dimensões (LUHMANN, 1985). Em certo sentido, a modernidade funda tanto a estratificação social em termos de classe quanto livra o indivíduo da determinação religiosa de suas ações (LUHMANN, 1985). Por conseguinte, se nas sociedades modernas - funcionalmente diferenciadas - os símbolos e emblemas responsáveis pela demarcação da origem social não funcionam mais como critério primário de distinção social, a formação das classes sociais e a expressão das vantagens 
ou desvantagens correlatas tornam-se crescentemente opacas em contextos de interação face a face (LUHMANN, 1985). Sob este prisma, tais hierarquias de status e de origem social perdem seu poder de regular, de modo imediato e explícito, as interações intersubjetivas (LUHMANN, 1985). Regras e procedimentos institucionais passam a operar a partir do princípio da igualdade formal, engendrando não apenas a illusio da meritocracia na qual se dissimulam vantagens de origem de classe, mas um contexto efetivo para ação. Seria possível pensar em procedimentos institucionais impessoalizados apenas sob a chave da illusio, de modo a encobrir a dominação simbólica? Ou será que o princípio da igualdade formal é condição operacional necessária ao funcionamento das instituições modernas? Como se desenrolaria a relação entre disposições, instituições, se a cada momento procedimental houvesse a rememoração do poder simbólico implícito ao contexto?

Podemos extrair duas consequências possíveis do diagnóstico de Luhmann: a) a primeira, sobre a qual Bourdieu ergue toda sua sociologia, a saber: o princípio de não transparência da operação e dos procedimentos impessoais responsáveis pela reprodução da desigualdade, dado que os agentes investem afetivamente em seu sucesso nos campos e instituições; b) a segunda contrária à primeira - reside na relativa indeterminação dos contextos de interação face a face devido ao fato de que a explicitação de símbolos distintivos não opera mais como critério primário, tampouco único de seleção e desclassificação social. É precisamente nesta zona ulterior que práticas e disposições, reafirmadas sucessivamente em contextos de atualização, ou em vigília (LAHIRE, 2001a), podem produzir caminhos divergentes daqueles previstos pela origem de classe.

Para Luhmann, por exemplo, a formação da desigualdade de classes consiste na maneira pela qual um conjunto de desvantagens de origem num subsistema funcionalmente diferenciado circunscreve (Umschreiben) e pode vir a prescrever um conjunto de condições desfavoráveis noutro subsistema. Não se trata apenas de igualdade de chances, mas no: “ (...) entrelaçamento (Bündelung) e no fortalecimento mútuo de tais tendências para a construção da desigualdade. Não se trata apenas de desigualdades como tal, mas de sua interdependência as quais podem ser identificadas como 'classe' (...) " (LUHMANN, 1985, p. 144). O problema posto por Luhmann, embora despido de uma sociologia disposicionalista, parece-nos muito semelhante ao questionamento de Lahire (2001b) acerca da pressuposição de transferência (transponibilité) e generalidade de um patrimônio de disposições. Dito de outro modo: em qual medida e extensão condições desfavoráveis e desvantajosas num campo ou subsistema funcionalmente diferenciado têm a capacidade de se "transferirem" para outros subsistemas, esferas de valor e campos? Ou então, a partir da terminologia lahiriana: em qual medida um patrimônio de disposições, formado num campo, torna-se generalizável à formação do gosto noutro campo? (LAHIRE, 2001b). Neste particular, parece-nos que, para Bourdieu (1979), a conciliação entre a multidimensionalidade da desigualdade, uma teoria de classes e da dominação simbólica de longo alcance ocorre justamente pela tendência geral de transposição das práticas e posições relativas de um campo ao outro. 
Há uma diferença de perspectivas. Para Bourdieu, a desigualdade de classe produzida na socialização familiar com o capital cultural e econômico consta como princípio geral de desvantagem nos campos, que embora operando com regras e normas relativamente autônomas, reforçam-se mutuamente. Com esse princípio geral de socialização, torna-se possível conciliar a multidimensionalidade da desigualdade com uma teoria social de longo alcance. Do contrário, seria impossível desenhar a representação abstrata da desigualdade, o conceito de espaço social. Não por acaso, as elites se caracterizam como aquelas capazes de mobilizar e concentrar capital cultural, econômico e social (espécies de capital) em alto volume. Muito embora as espécies de capital envolvam campos de capitalização operando em lógicas distintas, elas tendem a se reforçar mutuamente, formando um circuito de poder, ou o que Bourdieu chama de divisão do trabalho de dominação (BOURDIEU, 2000). Já em Luhmann (1985), a caracterização da desigualdade de classes é a resultante da interdependência relacional de condições desvantajosas ou de exclusão nos subsistemas funcionalmente diferenciados. A formação das classes sociais é produzida por um efeito resultante da acumulação comprovável de desvantagens sucessivas nos sistemas funcionalmente diferenciados, uma vez que a vulnerabilidade econômica circunscreve exclusão escolar que, por sua vez, influencia uma posição precária no mercado de trabalho. Conquanto a teoria de Bourdieu explique fenômenos de reprodução social da desigualdade de classes com mais precisão, a de Luhmann nos abre um caminho para compreender, de um lado a dinâmica de circunscrição de formas funcionalmente diferenciadas de desigualdade na formação das classes e, de outro, fenômenos nos quais a formação das classes implica algum grau de indeterminação. A seguir faremos um balanço conclusivo da discussão, com a finalidade de buscar caminhos que possam apontar para uma direção sintética.

\section{Balanço conclusivo}

Este artigo buscou problematizar três categorias de questões: a) a relação entre a formação das classes sociais e os processos de socialização de seus agentes; b) o liame entre origem familiar de classe e variações intraindividuais, uma vez que as últimas podem se tornar cruciais em momentos contingentes; c) ainda ao final da mesma seção discutimos como Bourdieu e Luhmann respondem à conciliação teórica entre diferenciação e desigualdade social.

Para Bernard Lahire (2001a, 2001b, 2012), a tarefa da sociologia disposicionalista é compor quadros analíticos empiricamente mais sofisticados, porquanto as variações intraindividuais devem contar como fator tão fundamental quanto a origem de classe. Ademais, o afrouxamento parcial entre as desigualdades reproduzidas na origem familiar e disposições, incorporada sem situações posteriores da trajetória do agente, permite maior significância às variações intraindividuais.

Em seguida discutimos o conceito de família introduzido por Bourdieu (1979, 1993). Identificamos a insuficiência de sua definição, destacando a família como ambiente de conflitos 
e de luta por interesses, sem perceber sua função normativa nas sociedades modernas. Ela centra-se em três pilares:1) na introjeção de um senso responsabilidade mútua entre os membros; 2) na incorporação de comportamentos disciplinares; 3) e no cuidado afetivo. São etapas absolutamente fundamentais na instauração de uma autorrelação prática positiva dos agentes, baseada em confiança e autoestima. Esta função socializadora tem igual relevância nos desdobramentos futuros nas trajetórias dos agentes. Apontamos então, introdutoriamente, as recentes características assumidas pela família e pressupostas no conceito aplicado por Bourdieu.

Por fim, juntamos o questionamento do desacoplamento parcial entre origem familiar de classe e ação social ao debate acerca da multidimensionalidade da desigualdade social. Tanto a flexibilização na relação entre origem de classe e ação social permite maior relevância das variações intraindividuais na trajetória dos atores quanto a concepção de desigualdade social como acumulação de desvantagens enfraquece a ideia da socialização familiar de classe como elemento sobredeterminante. Certamente, em sociedades periféricas e com extrema desigualdade como a brasileira, a formação das classes sociais exibe forte circunscrição de desvantagens em diferentes aspectos, sobretudo, o econômico, o educacional, o familiar e na saúde. Contudo, a desigualdade de classes brasileira não é estática, tampouco deve ser hipostasiada.

Seria ainda possível se perguntar pelo potencial real de circunscrição de desvantagens legadas pela socialização familiar primária. Ou seja: em vez de pressupor a correspondência entre a socialização familiar de classe e o reforço mútuo da dominação simbólica nos campos relativamente autônomos, a questão se endereçaria ao seguinte: qual o poder de circunscrição de desvantagens ou vantagens angariadas num contexto familiar de classe? Qual é a extensão do seu poder heurístico? Assim sendo, nosso intento foi contrapor a tese da variação intraindividual e da multidimensionalidade sistêmica da desigualdade ao modelo baseado na origem familiar de classe.

A finalidade central do artigo foi indagar criticamente o modelo teórico baseado na primazia unilateral da socialização primária na organização familiar, que, por sua vez, pode ser reenviada a uma posição de classe. Com isso, questionamos a tendência geral de reforço mútuo da dominação simbólica nos campos, muito embora constituam regras, procedimentos e valores específicos e relativamente autônomos. A reflexão crítica partiu tanto dos desenvolvimentos da sociologia disposicionalista de Lahire (2001a) quanto da concepção multidimensional de Luhmann (1985), que apresenta uma nuance importante na conciliação entre diferenciação funcional e estratificação social. Lahire apresenta recursos que questionam a sobredeterminação da família no sucesso escolar, enquanto Luhmann encara a multidimensinonalidade da desigualdade como circunscrição de desvantagens (ou vantagens), em vez de se fiar no reforço mútuo da dominação simbólica e econômica, inscrita nos campos relativamente autônomos. 


\section{Referências}

ABRANTES, P.; AMÂNDIO, S. Bernard Lahire e a sociologia da educação portuguesa. Educação, Sociedade \& Culturas, Porto, n. 42, p. 7-25, 2014.

ADORNO, W, T.Soziologische Schriften I. Berlin:Suhrkamp, Band I, 2003.

BERNSTEIN, B. Towards a theory of educational transmission. London/NewYork: Routledge, 1975.

BOURDIEU, P. Algérie 60:structures économiques et structures temporelles. Paris : Les Éditions de Minuit, 1977.

BOURDIEU, P. La Distinction: critique social du jugement. Paris: Minuit, 1979.

BOURDIEU, P. Pascalian Meditations. Stanford: Standford University Press, 2000.

BOURDIEU, P. À propos de la famille comme catégorie réalisée. Actes de la recherche en sciences sociales, Paris/ Liège, v. 100, p. 32-36, dez. 1993.Disponível em: http://www.persee.fr. Acesso em : 13 out. 2010.

BOURDIEU, P.; PASSERON, J-C. La reproduction: éléments pour une théorie du système d'enseignement. Paris:Éditions de Minuit, 1970.

CHAMBOREDON J-C ; PREVOT, J. « Le métier d’enfant »: Définition sociale de la prime enfance et fonctions différentielles de lécole maternelle.Revue française de sociologie, Paris/Liège, v. 14, n. 3, p. 295-335, 1973. Disponível em: http://www.persee.fr. Acesso em: 10 out. 2011

ELIAS, N; SCOTSON, J. Etablierte und Außenseiter. Erste Auflage. Frankfurt am Main: Suhrkamp Taschenbuch Verlag, 1993.

FROMM, Erich. Psychologische Aspekte zur Frage eines garantierten Einkommens füralle. In: FUNK, Rainer (org.). Gestamtausgabe in zwölfBänden. München: Deutscher Taschenbuch Verlag,1999. p.309-316

HONNETH, A. Kampf um Anerkennung, 7 Auflage, Frankfurt am Main: Suhrkamp Verlag, 2012.

LAHIRE, B. De la Théorie de l'habitus à une sociologie psychologique. In: LAHIRE, B. (org.). Le Travail Sociologique de Pierre Bourdieu: dettes et critiques. Paris: La Découverte, 2001a. p. 123-152

LAHIRE, B. Hors-Champ, Contrechamp. In: LAHIRE, B. Le Travail Sociologique de Pierre Bourdieu: dettes et critiques. Paris: La Découverte, 2001b. p. 23-57

LAHIRE, B. Tableaux de familles: Heurs et malheurs scolaires en milieux populaires. Paris: Éditions Gallimard/ Le Seuil, 2012.

LAHIRE, B. Homem Plural: os determinantes da ação. Petrópolis: Editora Vozes, 2002

LAHIRE, B. A Cultura dos Indivíduos. Porto Alegre: Artmed, 2006.

LUHMANN, N. Zum Begriff der sozialenKlasse. In: LUHMANN, N. (org.). Soziale Differenzierung: Zur Geschichteeiner Idee. Erste Auflage, Opladen: Westdeutscher: Verlag GmbH, 1985.

MACIEL F. Erich Fromm and the Culture of Contemporary Capitalism. In: SECOND INTERNATIONAL ERICH FROMM RESEARCH CONFERENCE, 2, 2018, Berlim. Fromm Forum. Tuebingen: Selbstverlag, 2019. p. 58-69.

Recebido em: 12/12/2018

Aceito em: 16/01/2019 